\title{
Does off-pump or minimally invasive coronary artery bypass reduce mortality, morbidity, and resource utilization when compared with percutaneous coronary intervention? A meta-analysis of randomized trials
}

\author{
Daniel Bainbridge, MD, FRCPC, ${ }^{a, *}$ Davy Cheng, MD, MSc, FRCPC, ${ }^{a, \dagger}$ Janet Martin, PharmD, ${ }^{b, \ddagger}$ \\ Richard Novick, MD, MSc, FRCSC, ${ }^{c, \S}$ and The Evidence-based Peri-operative Clinical Outcomes Research (EPiCOR) \\ Group
}

From the Departments of Anesthesia \& Perioperative Medicine ${ }^{\text {a; }}$ Pharmacy, Physiology \& Pharmacology ${ }^{\mathrm{b}}$; and Division of Cardiac Surgery, ${ }^{\mathrm{c}}$ London Health Sciences Centre, University of Western Ontario, London, Ontario, Canada.

Funding: Department of Anesthesia and Perioperative Medicine, University of Western Ontario and from an HTA Capacity Building Grant awarded by the Canadian Coordinating Office of Health Technology Assessment (CCOHTA). No funds were received from proprietary sources.

Ethics approval was not required for the conduct of this study.

Presented at the Health Technology Assessment International (HTAi) Conference in Rome, June 20-22, 2005.

Received for publication Sept 11, 2006; revisions received Oct 25, 2006; accepted for publication Nov 1, 2006.

Address for reprints: D. Cheng, MD, MSc, FRCPC, Department of Anesthesia \& Perioperative Medicine, London Health Sciences Centre-University Hospital, 339 Windermere Rd, Room 3-CA19, London, Ontario, Canada N6A 5A5 (E-mail davy. cheng@lhsc.on.ca).

*Assistant Professor.

$\dagger$ Professor and Chair, Department of Anesthesia.

$\ddagger$ Director, High Impact Technology Evaluation Centre (HiTEC).

§Professor and Head, Division of Cardiac Surgery.

J Thorac Cardiovasc Surg 2007;133:623-31

$0022-5223 / \$ 32.00$

Copyright $(92007$ by The American Association for Thoracic Surgery

doi:10.1016/j.jtcvs.2006.11.019
Objective: To determine, through meta-analysis, whether off-pump coronary artery bypass, including minimally invasive off-pump coronary artery bypass, improves short-term and midterm outcomes compared with percutaneous coronary intervention for single- or double-vessel coronary artery disease.

Methods: The primary outcome was need for coronary reintervention at 1 to 5 years. Secondary outcomes included all major clinical morbidities and resource utilization. A comprehensive search was undertaken to identify all randomized trials of off-pump coronary artery bypass versus percutaneous coronary intervention. MEDLINE, Cochrane Library, EMBASE, and abstract databases were searched up to May 2006. All randomized trials comparing off-pump coronary artery bypass (sternotomy or minimally invasive) versus percutaneous coronary intervention and reporting at least one predefined outcome were included. Odds ratios (OR, 95\% confidence intervals [CI]) and weighted mean differences (WMD, 95\% CI) were analyzed.

Results: Six trials involving 989 patients were included. Compared with percutaneous coronary intervention, off-pump coronary artery bypass decreased angina recurrence (OR $0.54,95 \%$ CI $0.34-0.87$ ) and need for reintervention at 1 to 5 years (OR $0.24,95 \%$ CI $0.15-0.40$ ). Major adverse coronary events were significantly reduced (OR $0.44,95 \%$ CI $0.30-0.63$ ) and event-free survival was significantly increased at 1 to 5 years (OR 2.32, 95\% CI 1.62-3.32) for off-pump coronary artery bypass versus percutaneous coronary intervention. Coronary stenosis at 6 months was reduced with off-pump coronary artery bypass compared with percutaneous coronary intervention (OR $0.31,95 \%$ CI $0.18-0.55)$. Hospital stay was significantly increased with off-pump coronary artery bypass versus percutaneous coronary intervention (WMD 4.03, 95\% CI 2.37-5.70). Quality of life favored off-pump coronary artery bypass in some domains but was reported in few studies. Death, myocardial infarction, and stroke did not significantly differ.

Conclusions: In single- or double-vessel disease, off-pump coronary artery bypass improved short-term and midterm clinical outcomes compared with percutaneous coronary intervention but was associated with an increased length of hospital stay.

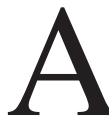
lthough it has been demonstrated that conventional coronary artery bypass surgery $(\mathrm{CCAB})$ may prolong life and reduce symptoms, these benefits are tempered by risks including mortality $(2 \%-5 \%)$, stroke $(2 \%)$, transfusions $(30 \%-90 \%)$, atrial fibrillation (30\%), and neurocognitive dysfunction $(50 \%-75 \%) .{ }^{1-4}$ 


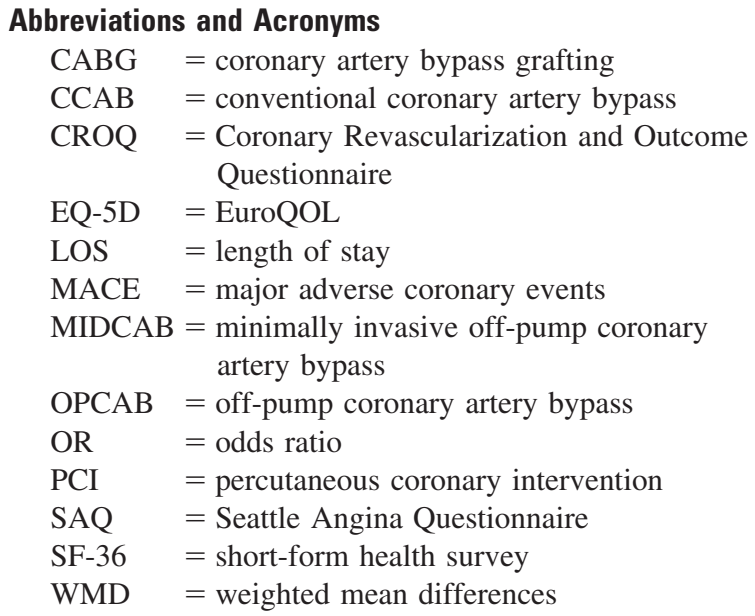

Consequently, there has been an upsurge of interest in safer alternatives to $\mathrm{CCAB}$, including percutaneous coronary intervention with stenting (PCI) and off-pump beating heart bypass surgery (OPCAB), with avoidance of cardiopulmonary bypass. ${ }^{5,6}$ Several randomized trials have compared PCI with $\mathrm{CCAB}$ and demonstrated increased rates of angina or need for reintervention in the PCI cohort, ${ }^{1,7-11}$ whereas overall costs were reduced in the short term. ${ }^{9}$ Outcomes with PCI were generally worse in patients with diabetes and in those with multivessel disease. ${ }^{12,13} \mathrm{PCI}$ is most commonly performed in limited target vessels; thus it may not be appropriate to compare its outcomes with multivessel CCAB. ${ }^{14}$

Comparisons of OPCAB and CCAB surgery have demonstrated improvement in short-term outcomes favoring $\mathrm{OPCAB}$ for atrial fibrillation, blood transfusion, and length of hospital stay in patients unselected for risk (ie, in mixed-risk patient populations). ${ }^{15}$ There is further evidence indicating OPCAB improves mortality, morbidity, and resource utilization when compared with $\mathrm{CCAB}$ in high-risk patients. ${ }^{16}$ However, patients undergoing OPCAB had slightly fewer anastomoses, suggesting some limitations for multiple target revascularizations using OPCAB surgical technique. ${ }^{15}$ Therefore, comparing PCI with OPCAB would seem the more relevant comparison in patients with one- or two-vessel coronary artery disease.

We sought to determine, through systematic review with meta-analysis of all relevant randomized trials, whether OPCAB reduces mortality, morbidity, or resource utilization when compared with PCI.

\section{Materials and Methods}

\section{Searching for Trials}

This meta-analysis was performed in accordance with QUOROM* recommendations and according to a protocol that pre-specified

*QUOROM $=$ Quality of Reporting of Meta-analyses, outcomes, search strategies, inclusion criteria, and statistical analyses. ${ }^{17} \mathrm{~A}$ search was undertaken in accordance with Cochrane Collaboration recommendations to identify all published or unpublished randomized trials of $\mathrm{OPCAB}$ versus $\mathrm{CCAB}$ or PCI, in any language. MEDLINE, Cochrane CENTRAL, EMBASE, Current Contents, DARE, NEED, and INAHTA ${ }^{\dagger}$ databases were searched from the date of their inception to May 2006. Search terms included variants of off-pump, minimally invasive, beating heart, and coronary artery bypass. Tangential electronic exploration of related articles and hand searches of bibliographies, scientific meeting abstracts, and related journals were also performed.

\section{Inclusion Criteria}

Studies were included if they met each of the following: (1) adult patients with single- or multiple-vessel coronary artery disease suitable for revascularization with either OPCAB or PCI; (2) randomized allocation to $\mathrm{OPCAB}$ on the beating heart (via thoracotomy or minimally invasive technique) versus PCI (with or without stenting); and (3) reporting at least one pertinent clinical or economic outcome. Blinded and unblinded studies were included, in any language. Hybrid (ie, OPCAB plus PCI) and robotically assisted surgery studies were excluded.

\section{Data Extraction}

Two authors independently identified trials for inclusion and extracted information on demographics, interventions, and outcomes. Authors of included trials were contacted when necessary to clarify data and to identify multiple publications. Two reviewers independently assigned each trial a Jadad quality score ${ }^{18}$ that evaluates randomization, blinding, and completeness of follow-up (maximum score, 5). Disagreements were resolved by consensus.

\section{End Points}

The primary outcome was defined as the need for reintervention for ischemia. Secondary outcomes included postoperative incidence of major adverse coronary events (MACE), all-cause mortality, stroke, acute myocardial infarction, atrial fibrillation, renal failure, need for inotropes, need for intra-aortic balloon pump, mediastinitis or wound infection, respiratory infections, angina recurrence, restenosis, need for transfusions, re-exploration for bleeding, neurocognitive dysfunction, intensive care unit (ICU) length of stay (LOS), hospital LOS, hospital costs, and quality of life (QOL). The original study authors' definition of MACE was used and usually included the composite of death, acute myocardial infarction, and need for reintervention, and sometimes included stroke. Reintervention for ischemia was defined as requirement for either PCI or CABG occurring anytime throughout the trial. Stenosis and atrial fibrillation were defined according to study authors' definitions. Acute myocardial infarction was defined per study authors' definitions of new-onset infarction using electrocardiographic or enzymatic criteria. Mediastinitis and wound infection were defined as deep or superficial wound infections of the chest or catheter-related infections; they excluded leg wound infections. Respiratory infection was defined according to authors' definitions, whether or not confirmed by chest x-ray film. Need for

$\dagger \mathrm{DARE}=$ Database of Abstracts of Reviews of Effects; NEED $=$ NHS Economic Evaluation Database; INAHTA = International Network of Agencies for Health Technology Assessment. 
a transfusion was defined as the number of patients requiring red blood cell transfusion. Renal failure was defined as a new rise in serum creatinine of more than $50 \%$, decline in creatinine clearance of more than $50 \%$, or requirement of dialysis. Since no standard definition exists for neurocognitive dysfunction, we planned to include only studies reporting neurocognitive dysfunction dichotomously, and when tests in accordance with the statement of consensus were used. ${ }^{19}$ Duration of ventilation was measured from the end of surgery to the time of tracheal extubation. ICU LOS and hospital LOS were measured from the end of surgery until ICU or hospital discharge, respectively.

\section{Statistical Analysis}

Outcomes were analyzed as dichotomous variables, with the exception of duration of ventilation, LOS, costs, and QOL, which were analyzed as continuous variables when the mean and standard deviation were reported. For dichotomous variables, odds ratios and $95 \%$ confidence intervals (OR, 95\% CI) were calculated. For continuous variables, the weighted mean difference (WMD, 95\% CI) was calculated for duration of ventilation and LOS. Standardized mean differences were planned to be calculated for costs and QOL; however, these outcomes were insufficiently reported for combined analyses. When significant differences were found for proportions, the absolute risk reduction and number needed to treat were calculated. ${ }^{20}$ Heterogeneity was explored using $\mathrm{I}^{2}$. The $\mathrm{I}^{2}$ indicates the proportion of variability between trials that cannot be attributable to chance alone; it provides an improved measure of hetereogeneity between trials that is not limited by power. ${ }^{21,22}$ Values of $\mathrm{I}^{2}$ higher than $50 \%$ were considered to indicate significant heterogeneity between trials.

For each outcome, the Mantel-Haenszel (fixed effect) or DerSimonian and Laird (random effects) model was used when $\mathrm{I}^{2}$ suggested lack $(\leq 50 \%)$ or presence $(>50 \%)$ of heterogeneity, respectively. Pooled effect estimates and heterogeneity between studies were analyzed by use of Comprehensive MetaAnalysis (Englewood, NJ, 2002) and RevMan (v4.2, Cochrane Collaboration, 2003). Other than for the Q-test, statistical significance was defined as $P<.05$ or a confidence interval that excluded the possibility of no effect. All tests of statistical significance were 2 -sided. Whenever possible, data analysis was by intention-to-treat.

Subgroup analysis was planned for single- versus multiplevessel disease and for drug-eluting stents versus bare metal stents. Sensitivity analysis was planned to explore the potential effect of trial quality, publication status, and patients excluded in non-intention-to-treat trials using a worst-case scenario assumption. Publication bias was explored through visual inspection of funnel plots in which the inverse of the estimated variance of the natural logarithm of the adjusted relative risk was plotted against the natural logarithm of the adjusted relative risk for each outcome. ${ }^{23}$

\section{Results}

A total of 11 papers reporting on 6 trials involving 989 patients provided data for this meta-analysis (Figure 1 and Table 1). ${ }^{24-34}$ The median Jadad score was 3 (range
Potentially relevant RCTs identified and screened for retrieval $(n=567)$

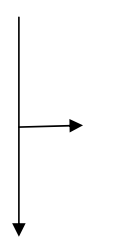

RCTs excluded ( $\mathrm{n}=553$ )

- non-random design, $\mathrm{n}=538$

- combined procedure, $n=2$

- robotic procedure, $\mathrm{n}=3$

- no off-pump group, $\mathrm{n}=9$

- no $\mathrm{PCl}$ group, $\mathrm{n}=1$

RCTs retrieved for more detailed evaluation

( $\mathrm{n}=14$ )

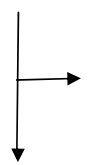

RCTs excluded ( $\mathrm{n}=4$ )

- non-random design, $\mathrm{n}=3$

- no $\mathrm{PCl}, \mathrm{n}=1$

Potentially appropriate RCTs to be included in the meta-analysis ( $\mathrm{n}=11)$

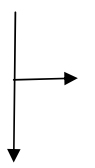

RCTs excluded from the metaanalysis, with reasons - Duplicate data, $n=5$

RCTs with usable information included in meta-analysis $(n=6)$

When duplicate studies provided new data beyond that available in the index publication, the additional data was included and attributed to the index trial. For this reason, multiple citations appear in Table 1 when one trial is reported across more than one paper.

Figure 1. Identification of eligible trials: OUOROM flow chart. RCTs, Randomized clinical trials; $\mathrm{PCl}$, percutaneous coronary intervention.

$2-3) .{ }^{18}$ Significant heterogeneity was found for reintervention at 6 months, angina recurrence at 6 months, and hospital LOS. Funnel plots showed no clear evidence of publication bias for any end point, although they were underpowered to do so. Patient demographics at baseline were similar (Table 2).

Although 5 of 6 trials comparing PCI versus OPCAB were exclusively of left anterior descending stenting versus left internal thoracic artery-to-left anterior descending anastomosis, one trial included patients with multivessel disease. ${ }^{33}$ The mean number of stents implanted per patient in this latter trial was $1.44 .^{33}$ The majority of stents were implanted for stenosis in the left anterior descending coronary artery. Five trials used MIDCAB technique in the majority of patients in the surgical arm. ${ }^{24,25,27,30,34}$ In one trial, surgical access to the heart was achieved via median 
TABLE 1. Characteristics of included trials

\begin{tabular}{|c|c|c|c|c|c|c|c|}
\hline Author & $\mathbf{N}$ & $\begin{array}{l}\text { Jadad } \\
\text { score }\end{array}$ & Vessels & Patients & Intervention & Year & Country \\
\hline $\begin{array}{l}\text { Cisowski }{ }^{25,26} \\
\quad(02)\end{array}$ & 100 & $2,0,1$ & 1 & $\begin{array}{l}\text { Isolated A-, B-type lesions of proximal } \\
\text { LAD }\end{array}$ & MIDCAB & $2000-2001$ & Poland \\
\hline $\begin{array}{l}\text { Diegeler }{ }^{27,28} \\
\quad \text { (02) }\end{array}$ & 220 & $2,0,1$ & 1 & $\begin{array}{l}\text { Isolated proximal LAD stenosis; elective, } \\
\quad \mathrm{EF}>35 \%\end{array}$ & MIDCAB & 1997-2001 & Germany \\
\hline $\begin{array}{l}\text { Drenth }^{29-32} \\
\quad(02)\end{array}$ & 102 & $2,0,1$ & 1 & $\begin{array}{l}\text { Isolated LAD stenosis of type B2 or C; } \\
\text { CCS class } 2 \text { or greater; first-time } \\
\text { CABG }\end{array}$ & MIDCAB & 1997-1999 & Netherlands \\
\hline $\begin{array}{l}\text { Eefting }^{33}(03) \\
\quad \text { (OctoStent) }\end{array}$ & 280 & $2,0,1$ & $\geq 1$ & $\begin{array}{l}\text { Included single- or multiple-vessel } \\
\text { disease, stable or unstable angina } \\
\text { (Braunwald class I-IIB). Excluded left } \\
\text { main stem stenosis, poor LVEF, } \\
\text { emergency revascularization, recent } \\
\text { MI, previous surgical } \\
\text { revascularization, or PCI within } 6 \text { mo }\end{array}$ & $\begin{array}{l}\text { OPCAB/ } \\
\text { MIDCAB }\end{array}$ & $1998-2000$ & Netherlands \\
\hline $\begin{array}{l}\text { Reeves }^{24} \text { (04) } \\
\quad \text { (AMIST) }\end{array}$ & 100 & $2,0,1$ & 1 & $\begin{array}{l}\text { Included isolated proximal LAD stenosis } \\
>50 \% \text {, elective or urgent. Excluded } \\
\text { emergency (required within } 24 \mathrm{~h} \text { ), } \\
\text { LVEF }<30 \% \text {, COPD, previous } \\
\text { revascularization, total occlusion of } \\
\text { LAD. }\end{array}$ & MIDCAB & 1999-2001 & $\begin{array}{l}\text { United } \\
\text { Kingdom }\end{array}$ \\
\hline Hong $^{34}(05)$ & 189 & $1,0,1$ & 1 & $\begin{array}{l}\text { Included isolated high-grade lesion } \\
\text { ( }>70 \% \text { of the luminal diameter) in } \\
\text { proximal LAD. Excluded AMI, prior } \\
\text { coronary revascularization, or total } \\
\text { occlusion of LAD }\end{array}$ & MIDCAB & 2003 & Korea \\
\hline $\begin{array}{l}\text { Summary, } \\
\text { OPCAB vs } \\
\text { PCI (6 } \\
\text { studies) }\end{array}$ & 989 & Median: 3 & $\geq 1$ & Mainly isolated LITA-LAD & $\begin{array}{l}\text { OPCAB/ } \\
\text { MIDCAB }\end{array}$ & 1997-2003 & $\begin{array}{l}\text { European/ } \\
\text { Asian }\end{array}$ \\
\hline
\end{tabular}

AMI, Acute myocardial infarction; AMIST, Angioplasty versus Minimally Invasive Surgery Trial; CABG, coronary artery bypass graft; $C C S$, Canadian Cardiovascular Society; $C O P D$, chronic obstructive pulmonary disease; $E F$, ejection fraction; $L A D$, left anterior descending; $L I T A$, left internal thoracic artery; $\angle V E F$, left ventricular ejection fraction; $M I$, myocardial infarction; $M I D C A B$, minimally invasive direct coronary artery bypass; OPCAB, off-pump coronary artery bypass; $\mathrm{PCl}$, percutaneous coronary intervention.

sternotomy in $67 \%$, left anterior thoracotomy in $30 \%$, and left posterolateral, xiphoid laparotomy, or partial sternotomy in the remainder. ${ }^{33}$ While one trial allowed either stenting or angioplasty, ${ }^{24}$ all patients except 6 in the PCI cohort received a stent. Five trials employed bare metal

TABLE 2. Patient characteristics

\begin{tabular}{lll}
\hline & OPCAB & PCI \\
\hline Age (mean y) & $58.9(9.8)$ & $58.2(10.1)$ \\
Female (\%) & 31 & 34 \\
Diabetic (\%) & 21 & 23 \\
History of MI (\%) & 29 & 32 \\
Smoker (\%) & 30 & 33 \\
Hyperlipidemia (\%) & 61 & 61 \\
Crossovers (\%) & 4.8 & 2.0
\end{tabular}

$\overline{M I}$, Myocardial infarction; OPCAB, off-pump coronary artery bypass; $P C l$, percutaneous coronary intervention. stents, ${ }^{24,25,27,30,33}$ whereas one trial ${ }^{34}$ used either sirolimuseluting (Cypher; Cordis, Roden, The Netherlands) or paclitaxel-eluting (Taxus; Boston Scientific, Galway, Ireland) stents. Anticoagulation after stent placement consisted of ticlopidine/clopidogrel and aspirin in 5 trials, ${ }^{24,25,27,30,34}$ and was not stated in one trial. ${ }^{33}$ Ticlopidine/clopidogrel was maintained for 4 weeks in the case of bare metal stents and 6 months for drug-eluting stents. Crossovers from $\mathrm{OPCAB}$ to PCI occurred in $4.8 \%$ of patients, whereas crossovers from PCI to OPCAB occurred in $2.0 \%$ of patients after randomization.

Table 3 and Figures 2 to 4 outline the results. Compared with PCI, OPCAB reduced the risk of reintervention for ischemia at 1 to 5 years by $76 \%$ (OR $0.24,95 \%$ CI 0.15-0.40). The odds of reintervention did not differ in hospital (OR $0.77,95 \%$ CI $0.35-1.68$ ) or at 6 months (OR 0.45, 95\% CI 0.16-1.29). Angina recurrence was significantly reduced in favor of OPCAB in hospital (OR 
TABLE 3. Results

\begin{tabular}{|c|c|c|c|c|c|}
\hline Outcome & OРCAB (\%) & PCI (\%) & OR $(95 \% \mathrm{CI})$ & $I^{2}(\%)$ & $P$ value for effect \\
\hline Death, in hospital & 1.3 & 0.4 & $2.01(0.56-7.23)$ & 0 & .28 \\
\hline Death, 6 months & 2.5 & 1.5 & $1.61(0.51-5.05)$ & 0 & .42 \\
\hline Death, 1 to 5 years & 5.9 & 3.5 & $1.51(0.72-3.18)$ & 20 & .27 \\
\hline AMI, in hospital & 3.0 & 2.9 & $1.11(0.5-2.47)$ & 0 & .8 \\
\hline AMI, 6 months & 2.8 & 3.4 & $0.93(0.35-2.49)$ & 17 & .81 \\
\hline AMI, 1 to 5 years & 4.0 & 4.8 & $0.92(0.45-1.9)$ & 0 & .82 \\
\hline Stroke, in hospital & 0.5 & 0.3 & $1.56(0.29-8.34)$ & 0 & .61 \\
\hline Stroke, 6 months & 0.6 & 1.9 & $0.43(0.6-2.95)$ & 0 & .39 \\
\hline Stroke, 1 to 5 years & 0 & 1.1 & $0.35(0.03-3.97)$ & 0 & .4 \\
\hline Angina recurrence, in hospital & 6.8 & 13.8 & $0.42(0.25-0.71)$ & 0 & $<.0001$ \\
\hline Angina recurrence, 6 months & 13.1 & 18.7 & $0.57(0.25-1.28)$ & 66 & .17 \\
\hline Angina recurrence, 1 to 5 years & 12.8 & 23.3 & $0.54(0.34-0.87)$ & 38 & .01 \\
\hline Reintervention, in hospital & 2.3 & 3.2 & $0.77(0.35-1.68)$ & 0 & .51 \\
\hline Reintervention, 6 months & 6.8 & 15.2 & $0.45(0.16-1.29)$ & 60 & .14 \\
\hline Reintervention, 1 to 5 years & 5.8 & 19.7 & $0.24(0.15-0.40)$ & 0 & $<.0001$ \\
\hline MACE, in hospital & 2.8 & 3.8 & $0.86(0.27-2.74)$ & 22 & .80 \\
\hline MACE, 6 months & 8.9 & 21.6 & $0.40(0.23-0.69)$ & 25 & $<.001$ \\
\hline MACE, 1 to 5 years & 14.3 & 26.8 & $0.44(0.30-0.63)$ & 0 & $<.0001$ \\
\hline Event-free survival, 6 months & 87.6 & 73.7 & $2.53(1.50-4.27)$ & 0 & $<.0001$ \\
\hline Event-free survival, 1 to 5 years & 83.8 & 69.9 & $2.32(1.62-3.32)$ & 0 & $<.0001$ \\
\hline Stenosis, 6 months & 10.3 & 28.0 & $0.31(0.18-0.55)$ & 47 & $<.0001$ \\
\hline Wound complications, in hospital & 3.5 & 0.9 & $2.54(0.62-10.45)$ & 0 & .20 \\
\hline
\end{tabular}

$A M I$, Acute myocardial infarction; $C l$, confidence intervals; $M A C E$, major adverse coronary events; $O P C A B$, off-pump coronary artery bypass; $O R$, odds ratio; $\mathrm{PCl}$, percutaneous coronary intervention.

$0.42,95 \%$ CI $0.25-0.71)$ and at 1 to 5 years (OR 0.54 , 95\% CI 0.34-0.87), but not at 6 months (OR 0.57, 95\% CI 0.25-1.28). MACE was significantly reduced in favor of OPCAB at 6 months (OR 0.40, 95\% CI 0.23-0.69) and at 1 to 5 years $(0.44,95 \%$ CI $0.30-0.63)$. Event-free survival was significantly improved at 6 months and at 1 to 5 years (Table 3 ). Six-month stenosis rates were significantly reduced (OR $0.31,95 \%$ CI $0.18-0.55$ ). However, hospital LOS was significantly increased with OPCAB versus PCI (WMD 4.0, 95\% CI 2.4-5.7). When subgroup analysis was performed for trials using bare metal stents and excluding studies using drug-eluting stents, the results did not materially change with the exception of reintervention at 6 months, which was sig- nificantly reduced in favor of OPCAB (OR $0.26,95 \%$ CI 0.14-0.49) (Table 4).

Compared with PCI, all-cause mortality, stroke, myocardial infarction, and wound complications were not reduced with OPCAB at any time point (Table 3 ). Other outcomes including atrial fibrillation, renal dysfunction, inotropic requirements, need for intra-aortic balloon pump, blood transfusion requirements, re-exploration for bleeding, ICU LOS, and neurocognitive function were insufficiently reported to perform meta-analysis.

QOL

QOL was measured in 2 studies, and results were not combined through meta-analysis because different QOL

\begin{tabular}{|c|c|c|c|c|c|c|c|c|c|c|c|c|c|}
\hline & Citation & Treated & Control & Effect & Lower & Upper & P Value & 0.1 & 0.2 & 0.5 & 1 & 2 & $\mathbf{5}$ \\
\hline & Cisowski 02 & $3 / 50$ & $11 / 50$ & .23 & .06 & .87 & .02 & & & & & & \\
\hline & Diegeler 02 & $11 / 108$ & $35 / 108$ & .24 & 11 & .50 & .00 & & & & & & \\
\hline & Drenth 02 & $3 / 51$ & $9 / 51$ & .29 & .07 & 1.15 & .07 & & & & & & \\
\hline & Eefting (OctoStent) 03 & 6/142 & $21 / 138$ & .25 & .10 & .63 & .00 & & & & & & \\
\hline & Reeves (AMIST) 04 & $0 / 49$ & $2 / 49$ & 19 & .01 & 4.10 & .24 & & & & & & \\
\hline Fixed & Combined (5) & $23 / 400$ & $78 / 396$ & .24 & .15 & .40 & .00 & & & & & & \\
\hline Random & Combined (5) & $23 / 400$ & $78 / 396$ & .24 & .15 & .40 & .00 & & & & & & \\
\hline
\end{tabular}

Figure 2. Reintervention at 1 to 5 years: OPCAB versus PCI. OPCAB, off-pump coronary artery bypass; PCI, percutaneous coronary intervention. 


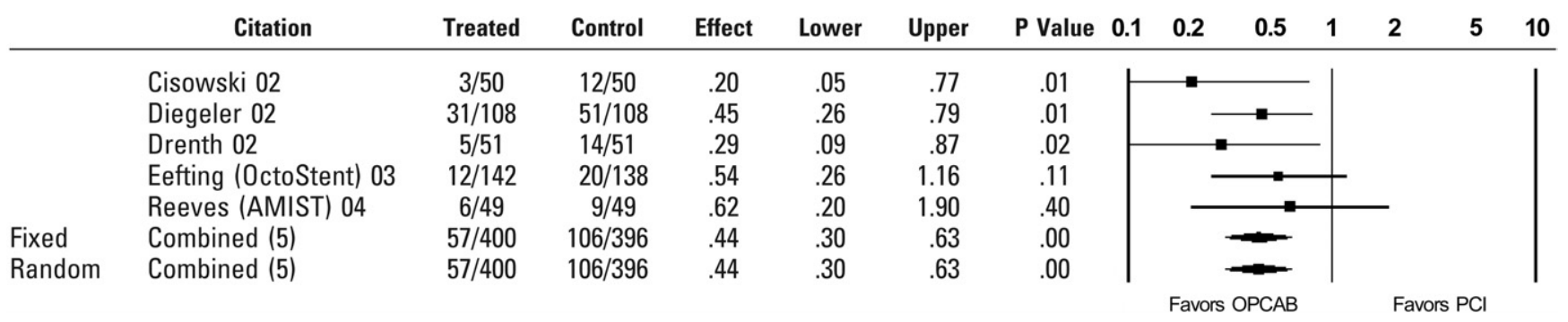

Figure 3. MACE at 1 to 5 years: OPCAB versus $\mathrm{PCI}$. MACE, major adverse coronary events; OPCAB, off-pump coronary artery bypass; $\mathrm{PCl}$, percutaneous coronary intervention.

scales were used. Eefting and associates $^{33}$ measured EuroQOL (EQ-5D) and short-form health survey (SF-36) and found that at 1 month, EQ-5D and many domains of the SF-36 were significantly higher after PCI than after $\mathrm{OPCAB}$, but this difference was no longer found at 1 year. In addition, Reeves and colleagues ${ }^{24}$ found that EQ-5D, SF-36, Seattle Angina Questionnaire (SAQ) and Coronary Revascularization and Outcome Questionnaire (CROQ) at 3 months, 6 months, and 12 months tended to favor OPCAB, although only three domains reached statistical significance (SF-36 mental composite score at 12 months, $P=.04$; SAQ treatment satisfaction score at 3 months, $P=.02$; CROQ cognitive score at 3 months, $P=.04$ ). SAQ dimensions of angina stability and frequency and CROQ physician and cognitive dimensions suggest the most consistent benefit of OPCAB, but without statistical significance. Since a large number of comparisons were tested for QOL domains, the finding of statistical significance should be interpreted with caution owing to the increased risk of spurious positive findings with multiple testing. Eefting and colleagues ${ }^{33}$ found an estimated gain in quality-adjusted life-years was 0.82 after PCI and 0.79 after OPCAB, and Reeves and coworkekrs $^{24}$ estimated gain in quality-adjusted life-years of 0.77 after PCI and 0.82 after OPCAB.

\section{Economic Outcomes}

Three trials reported economic outcomes. ${ }^{24,25,33}$ When direct costs during hospitalization or up to 1 year were considered, OPCAB was more costly than PCI, despite the added costs of increased reinterventions with PCI over 6- to 12-month follow-up (Table 5). Estimates of incremental cost-effectiveness were reported in 2 trials, with widely varying results (Table 6). Pooled analysis of economic outcomes was not practical owing to differences in methods of collecting and reporting costs.

\section{Discussion}

Compared with PCI, OPCAB decreased the odds of reintervention by $76 \%$, recurrent angina by $46 \%$, and occur-

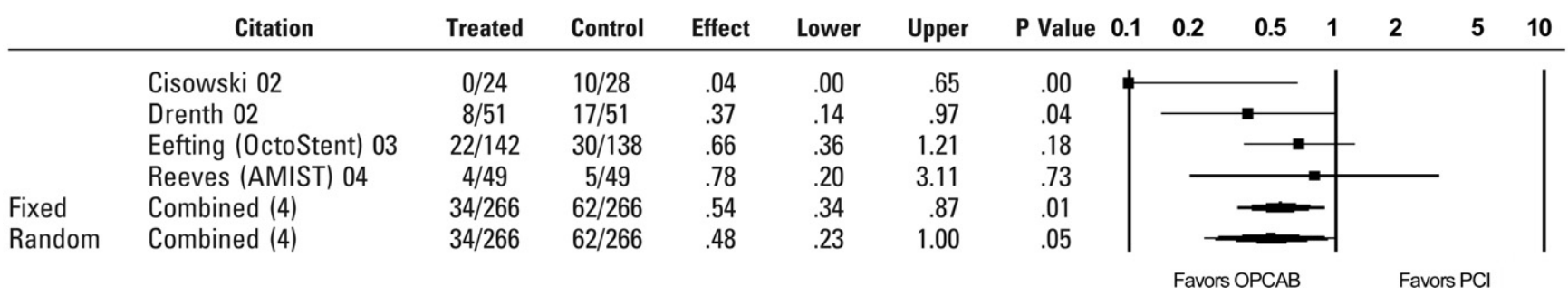

Figure 4. Angina recurrence at 1 to 5 years: OPCAB versus PCI. OPCAB, off-pump coronary artery bypass; $P C I$, percutaneous coronary intervention.

TABLE 4. Subgroup analysis: Bare metal stent angioplasty (excluding drug-eluting stents)

\begin{tabular}{lccccc}
\hline Outcome & OPCAB $(\%)$ & PCI (\%) & OR (95\% CI) & $\mathbf{I}^{2}(\%)$ & $\boldsymbol{P}$ value for effect \\
\hline Angina recurrence, in hospital & 6.8 & 13.8 & $0.42(0.25-0.71)$ & 0 & $<.0001$ \\
Angina recurrence, 1 to 5 years & 12.8 & 23.3 & $0.25(0.12-0.54)$ & 0 & $<.0001$ \\
Reintervention, 1 to 5 years & 3.7 & 13.4 & $0.25(0.12-0.54)$ & 0 & $<.0001$
\end{tabular}

$O P C A B$, off-pump coronary artery bypass; $P C l$, percutaneous coronary intervention; $O R$, operating room; $C l$, confidence interval. 
TABLE 5. Direct costs during hospitalization (or up to 1 year)

\begin{tabular}{lccc}
\hline Study & $\begin{array}{c}\text { OPCAB mean direct cost } \\
\text { (SD) per patient }\end{array}$ & $\begin{array}{c}\text { PCI mean direct cost } \\
\text { (SD) per patient }\end{array}$ & Summary \\
\hline Cisowski $^{25}$ (02) & 2000 USD at $30 \mathrm{~d}$ & $1600 \mathrm{USD}$ at $30 \mathrm{~d}$ & MIDCAB $>\mathrm{PCI} ; P$ not reported \\
Eefting $^{33}$ (03) (OctoStent) & 7508 EUR in hospital & $5013 \mathrm{EUR}$ in hospital & OPCAB $>\mathrm{PCl} ; P<.01$ \\
& (9518 EUR at $1 \mathrm{y})$ & (7043 EUR at $1 \mathrm{y}$ ) & OPCAB $>\mathrm{PCl} ; P<.01$ \\
Reeves $^{24}$ (02) & $2114 \mathrm{GBP}$ in hospital & $1093 \mathrm{GBP}$ in hospital & OPCAB $>\mathrm{PCl} ; P$ not reported \\
& $2681 \mathrm{GBP}$ at $1 \mathrm{y}$ & $1789 \mathrm{GBP}$ at $1 \mathrm{y}$ & OPCAB $>\mathrm{PCl} ; P$ not reported
\end{tabular}

EUR, Euro; $G B P$, Great Britain pound; $O P C A B$, off-pump coronary artery bypass; $P C l$, percutaneous coronary intervention; $S D$, standard deviation; USD, US dollars.

rence of MACE by $56 \%$ at 1 to 5 years, requiring an average hospital LOS that is 4 days or greater.

These results have significant implications when projected over a large population. For example, given the aggregate estimates in this meta-analysis, for every 1000 low-risk patients undergoing off-pump surgery (ie, primarily left internal thoracic artery-left anterior descending artery revascularization), there will be an estimated 105 fewer patients with angina, 143 fewer patients requiring reintervention, and 125 fewer patients with MACE at 1 to 5 years. Whether OPCAB increases or decreases overall costs over the midterm to long-term relative to PCI remains uncertain, because few studies reported resource utilization.

Studies comparing CCAB and PCI (angioplasty) have demonstrated an improvement in short-term outcomes with PCI, such as length of hospital stay and cost. Unfortunately, patients randomized to PCI typically experience higher rates of recurrent angina requiring repeat revascularization procedures. The largest trial to date of angioplasty versus $\mathrm{CCAB}$, the BARI trial (Bypass Angioplasty Revascularization Investigation), demonstrated that patients who had diabetes or multiple-vessel disease derived the greatest benefit from $\mathrm{CCAB} .{ }^{12,13}$ Although trials comparing percutaneous coronary stenting and $\mathrm{CCAB}$ have demonstrated a reduction in recurrent angina and restenosis compared with angioplasty, they still do not demonstrate equivalent efficacy to CCAB in these outcomes. ${ }^{7,9,35}$ The recent introduction of drug-eluting stents may further reduce the occurrence of recurrent angina and restensois ${ }^{36,37}$; however, it is still unclear whether they will prove equivalent to $\mathrm{CCAB}$ procedures. Comparisons of drug-eluting stents to $\mathrm{CCAB}$ may be incomplete until optimal drug dosage and delivery have been ascertained, and one drug-eluting stent may not be equally efficacious to others. ${ }^{36,37}$

Unfortunately, economic outcomes were insufficiently reported in the present review to allow for conclusions regarding incremental cost-effectiveness for OPCAB and PCI. Although initial costs favor PCI over CCAB, follow-up costs related to repeat revascularization reduce any economic advantage of PCI. ${ }^{38}$ The use of drug-eluting stents, which reduces the need for revascularization, may potentially reduce these reintervention costs related to PCI. However, numerous studies have suggested that drugeluting stents, at current prices, are not likely to be considered cost-effective. ${ }^{39-41}$ Indeed, a cost-effectiveness analysis from the province of Ontario, Canada, found that the incremental cost of drug-eluting stents compared with bare metal stents for 1 quality-adjusted life-year was $\$ 223,580$ Canadian dollars in non-post myocardial infarction diabetic patients having discrete lesions and $\$ 477,736$ Canadian dollars in these same patients with long or narrow lesions. ${ }^{42}$

Whereas the short-term and medium-term benefits of OPCAB surgery seem clear in the hands of experienced surgeons, ${ }^{15,16}$ the long-term results are too infrequently reported in the current literature to draw definitive conclusions. Of particular concern is graft patency, which has been demonstrated to be inferior in one randomized trial of OPCAB versus $\mathrm{CCAB}^{43}$ and not inferior in several other randomized trials. ${ }^{44-46}$ Although OPCAB initially was introduced with widespread enthusiasm, its frequency seems to have reached a plateau and it is being reserved increasingly for higher-risk patients with significant aortic disease. ${ }^{16}$

TABLE 6. Cost-effectiveness

\begin{tabular}{lcrr}
\hline Study & OPCAB total* cost per QALY & PCI total* cost per QALY & Incremental cost per QALY \\
\hline Eefting $^{33}$ (03) (OctoStent) & $1,1209 / 0.79$ & $\$ 8276 / 0.82$ & $-2933 / 0.03=-97,767 \mathrm{EUR} / 0 \mathrm{ALY}$ \\
Reeves $^{24}$ (04) & $2681 / 0.82$ & $1789 / 0.77$ & $892 / 0.02=+44,600 \mathrm{GBP} / 0 \mathrm{ALY}$ \\
\hline
\end{tabular}

EUR, Euro; $G B P$, Great Britain pound; $O P C A B$, off-pump coronary artery bypass; $P C I$, percutaneous coronary intervention; $Q A L Y$, quality-adjusted life year. $*$ Direct + indirect costs at 1 year. 
Given an increasing number of options for treatment of coronary artery disease, the need to identify subgroups of patients who benefit from a specific treatment option becomes imperative. The challenge is in balancing short- and long-term risk with benefits.

\section{Strengths, Limitations, and Generalizability}

Most trials for OPCAB versus PCI included only patients with single-vessel disease of the left anterior descending coronary artery, precluding inferences to patients with multivessel disease. Whether drug-eluting stents, which have been shown to significantly reduce restenosis and repeat revascularization rates by up to $83 \%$, would mitigate the observed differences in restenosis and reintervention between OPCAB and PCI remains to be addressed. ${ }^{47}$ However, randomized studies of drug-eluting stents have failed to demonstrate improvements in rates of mortality or myocardial infarction. ${ }^{36}$

The rigor of this meta-analysis, as evidenced by comprehensive searches for randomized trials of all relevant outcomes and comparisons in any language, and the adherence to QUOROM recommendations, serves to increase confidence that this represents a complete summary of best available evidence. When heterogeneity was accounted for statistically, the conclusions remained unchanged for each heterogeneous outcome. Although the median Jadad quality score was 3 out of 5 , this is common for meta-analysis of randomized trials (especially those in the field of surgery) and does not necessarily mean the trials were of low quality, but rather that key methodologic details were not reported. ${ }^{48}$

Although our analysis delineates the landscape of existing evidence, it also serves to highlight gaps that remain. Most notable is the lack of research defining long-term clinical, economic, and QOL outcomes associated with differing revascularization techniques. Accordingly, theoretical concerns about the quality and patency of grafts performed on the beating heart have not been adequately addressed by long-term follow-up of randomized trials to date, although survival and reintervention rates at up to 5 years have been encouraging (Table 3). Also notable is the lack of randomized controlled studies in higher-risk patients.

\section{Conclusions}

In conclusion, OPCAB reduces the need for reintervention, angina recurrence, and incidence of MACE at 1 to 5 years when compared with PCI. The overall impact on QOL and health system resource utilization remains unknown and warrants further study.

\section{References}

1. SOS. Coronary artery bypass surgery versus percutaneous coronary intervention with stent implantation in patients with multivessel cor- onary artery disease (the Stent or Surgery trial): a randomised controlled trial. Lancet. 2002;360:965-70.

2. Stover EP, Siegel LC, Parks R, Levin J, Body SC, Maddi R, et al. Variability in transfusion practice for coronary artery bypass surgery persists despite national consensus guidelines: a 24-institution study. Institutions of the Multicenter Study of Perioperative Ischemia Research Group. Anesthesiology. 1998;88:327-33.

3. Stamou SC, Hill PC, Dangas G, Pfister AJ, Boyce SW, Dullum MK, et al. Stroke after coronary artery bypass: incidence, predictors, and clinical outcome. Stroke. 2001;32:1508-13.

4. Mathew JP, Parks R, Savino JS, Friedman AS, Koch C, Mangano DT, et al. Atrial fibrillation following coronary artery bypass graft surgery: predictors, outcomes, and resource utilization. MultiCenter Study of Perioperative Ischemia Research Group. JAMA. 1996;276:300-6.

5. Rose EA. Off-pump coronary-artery bypass surgery. $N$ Engl J Med. 2003;348:379-80.

6. Ascione R, Caputo M, Angelini GD. Off-pump coronary artery bypass grafting: not a flash in the pan. Ann Thorac Surg. 2003;75:306-13.

7. Hannan EL, Racz MJ, Walford G, Jones RH, Ryan TJ, Bennett E, et a;l. Long-term outcomes of coronary-artery bypass grafting versus stent implantation. N Engl J Med. 2005;352:2174-83.

8. Goy JJ, Eeckhout E, Burnand B, Vogt P, Stauffer JC, Hurni M, et al. Coronary angioplasty versus left internal mammary artery grafting for isolated proximal left anterior descending artery stenosis. Lancet. 1994;343:1449-53.

9. Serruys PW, Unger F, Sousa JE, Jatene A, Bonnier HJ, Schonberger JP, et al. Comparison of coronary-artery bypass surgery and stenting for the treatment of multivessel disease. N Engl J Med. 2001;344: 1117-24.

10. Hamm CW, Reimers J, Ischinger T, Rupprecht HJ, Berger J, Bleifeld W. A randomized study of coronary angioplasty compared with bypass surgery in patients with symptomatic multivessel coronary disease. German Angioplasty Bypass Surgery Investigation (GABI). N Engl J Med. 1994;331:1037-43.

11. BARI investigators. Comparison of coronary bypass surgery with angioplasty in patients with multivessel disease. The Bypass Angioplasty Revascularization Investigation (BARI) Investigators. $N$ Engl J Med. 1996;335:217-25.

12. Berger PB, Velianou JL, Aslanidou Vlachos H, Feit F, Jacobs AK, Faxon DP, et al. Survival following coronary angioplasty versus coronary artery bypass surgery in anatomic subsets in which coronary artery bypass surgery improves survival compared with medical therapy. Results from the Bypass Angioplasty Revascularization Investigation (BARI). J Am Coll Cardiol. 2001;38:1440-9.

13. BARI investigators. Seven-year outcome in the Bypass Angioplasty Revascularization Investigation (BARI) by treatment and diabetic status. J Am Coll Cardiol. 2000;35:1122-9.

14. CABRI Trial Participants. First-year results of CABRI (Coronary Angioplasty versus Bypass Revascularisation Investigation). Lancet. 1995;346:1179-84.

15. Cheng DC, Bainbridge D, Martin JE, Novick RJ. Does off-pump coronary artery bypass reduce mortality, morbidity, and resource utilization when compared with conventional coronary artery bypass? A meta-analysis of randomized trials. Anesthesiology. 2005;102:188203.

16. Puskas J, Cheng D, Knight J, Angelini G, DeCannier D, Diegheler A, et al. Off-pump versus conventional coronary artery bypass grafting: a meta-analysis and consensus statement from the 2004 ISMICS Consensus Conference. Innovations. 2005;1:3-27.

17. Moher D, Cook DJ, Eastwood S, Olkin I, Rennie D, Stroup DF Improving the quality of reports of meta-analyses of randomised controlled trials: the QUOROM statement. Quality of Reporting of Meta-analyses. Lancet. 1999;354:1896-900.

18. Jadad AR, Moore RA, Carroll D, Jenkinson C, Reynolds DJ, Gavaghan DJ, et al. Assessing the quality of reports of randomized clinical trials: is blinding necessary? Control Clin Trials. 1996;17: $1-12$.

19. Murkin JM, Newman SP, Stump DA, Blumenthal JA. Statement of consensus on assessment of neurobehavioral outcomes after cardiac surgery. Ann Thorac Surg. 1995;59:1289-95. 
20. Altman DG. Confidence intervals for the number needed to treat. $B M J$. 1998;317:1309-12.

21. Higgins JP, Thompson SG, Deeks JJ, Altman DG. Measuring inconsistency in meta-analyses. BMJ. 2003;327:557-60.

22. Higgins JP, Thompson SG. Quantifying heterogeneity in a metaanalysis. Stat Med. 2002;21:1539-58.

23. Egger M, Davey Smith G, Schneider M, Minder C. Bias in metaanalysis detected by a simple, graphical test. BMJ. 1997;315:629-34.

24. Reeves BC, Angelini GD, Bryan AJ, Taylor FC, Cripps T, Spyt TJ, et al. A multi-centre randomised controlled trial of minimally invasive direct coronary bypass grafting versus percutaneous transluminal coronary angioplasty with stenting for proximal stenosis of the left anterior descending coronary artery. Health Technol Assess. 2004;8: $1-43$.

25. Cisowski M, Drzewiecki J, Drzewiecka-Gerber A, Jaklik A, Kruczak W, Szczeklik M, et al. Primary stenting versus MIDCAB: preliminary report-comparison of two methods of revascularization in single left anterior descending coronary artery stenosis. Ann Thorac Surg. 2002; 74:S1334-9.

26. Cisowski M, Drzewiecka-Gerber A, Ulczok R, Abu Samra R, Drzewiecki J, Guzy M, et al. Primary direct stenting versus endoscopic atraumatic coronary artery bypass surgery in patients with proximal stenosis of the left anterior descending coronary artery-a prospective, randomised study. Kardiol Pol. 2004;61:253-61; discussion 62-4.

27. Diegeler A, Thiele H, Falk V, Hambrecht R, Spyrantis N, Sick P, et al. Comparison of stenting with minimally invasive bypass surgery for stenosis of the left anterior descending coronary artery. $N$ Engl J Med. 2002;347:561-6.

28. Thiele H, Oettel S, Jacobs S, Hambrecht R, Sick P, Gummert JF, et al. Comparison of bare-metal stenting with minimally invasive bypass surgery for stenosis of the left anterior descending coronary artery: a 5-year follow-up. Circulation. 2005;112:3445-50.

29. Drenth DJ, Veeger NJ, Winter JB, Grandjean JG, Mariani MA, Boven van $\mathrm{AJ}$, et al. A prospective randomized trial comparing stenting with off-pump coronary surgery for high-grade stenosis in the proximal left anterior descending coronary artery: three-year follow-up. J Am Coll Cardiol. 2002;40:1955-60.

30. Drenth DJ, Winter JB, Veeger NJ, Monnink SH, van Boven AJ, Grandjean JG, et al. Minimally invasive coronary artery bypass grafting versus percutaneous transluminal coronary angioplasty with stenting in isolated high-grade stenosis of the proximal left anterior descending coronary artery: six months' angiographic and clinical follow-up of a prospective randomized study. J Thorac Cardiovasc Surg. 2002;124:130-5.

31. Drenth DJ, Veeger NJ, Grandjean JG, Mariani MA, van Boven AJ, Boonstra PW. Isolated high-grade lesion of the proximal LAD: a stent or off-pump LIMA? Eur J Cardiothorac Surg. 2004;25:567-71.

32. Drenth DJ, Veeger NJ, Middel B, Zijlstra F, Boonstra PW. Comparison of late (four years) functional health status between percutaneous transluminal angioplasty intervention and off-pump left internal mammary artery bypass grafting for isolated high-grade narrowing of the proximal left anterior descending coronary artery. Am J Cardiol. 2004;94:1414-7.

33. Eefting F, Nathoe H, van Dijk D, Jansen E, Lahpor J, Stella P, et al. Randomized comparison between stenting and off-pump bypass surgery in patients referred for angioplasty. Circulation. 2003;108: 2870-6.
34. Hong SJ, Lim DS, Seo HS, Kim YH, Shim WJ, Park CG, et al. Percutaneous coronary intervention with drug-eluting stent implantation vs. minimally invasive direct coronary artery bypass (MIDCAB) in patients with left anterior descending coronary artery stenosis. Catheter Cardiovasc Interv. 2005;64:75-81.

35. Malenka DJ, Leavitt BJ, Hearne MJ, Robb JF, Baribeau YR, Ryan TJ, et al. Comparing long-term survival of patients with multivessel coronary disease after CABG or PCI: analysis of BARI-like patients in northern New England. Circulation. 2005;112(9 Suppl):I371-6.

36. Babapulle MN, Joseph L, Belisle P, Brophy JM, Eisenberg MJ. A hierarchical Bayesian meta-analysis of randomised clinical trials of drug-eluting stents. Lancet. 2004;364:583-91.

37. Silber S. Paclitaxel-eluting stents: are they all equal? An analysis of six randomized controlled trials in de novo lesions of 3,319 patients. J Interv Cardiol. 2003;16:485-90.

38. Yock CA, Boothroyd DB, Owens DK, Garber AM, Hlatky MA. Cost-effectiveness of bypass surgery versus stenting in patients with multivessel coronary artery disease. Am J Med. 2003;115:382-9.

39. Ward MR. Cost-benefit of drug eluting stents-time for a reality check. Heart Lung Circ. 2005;14:74-7.

40. Hill R, Bagust A, Bakhai A, Dickson R, Dundar Y, Haycox A, et al. Coronary artery stents: a rapid systematic review and economic evaluation. Health Technol Assess 2004;8:iii-iv, 1-242.

41. Kaiser C, Brunner-La Rocca HP, Buser PT, Bonetti PO, Osswald S, Linka A, et al. Incremental cost-effectiveness of drug-eluting stents compared with a third-generation bare-metal stent in a real-world setting: randomised Basel Stent Kosten Effektivitats Trial (BASKET). Lancet. 2005;366:921-9.

42. Bowen J, Hopkins R, He Y, Blackhouse G, Lazzam C, Tu J, et al. Systematic review and cost-effectiveness analysis of drug eluting stents compared to bare metal stents for percutaneous coronary interventions in Ontario. Interim Report for the Ontario Ministry of Health and Long-term Care. Hamilton [ON]: Program for Assessment of Technology in Health, 2005.

43. Khan NE, De Souza A, Mister R, Flather M, Clague J, Davies S, et al. A randomized comparison of off-pump and on-pump multivessel coronary-artery bypass surgery. N Engl J Med. 2004;350:21-8.

44. Lingaas PS, Hol PK, Lundblad R, Rein KA, Tonnesen TI, Svennevig $\mathrm{JL}$, et al. Clinical and angiographic outcome of coronary surgery with and without cardiopulmonary bypass: a prospective randomized trial. Heart Surg Forum. 2004;7:37-41.

45. Puskas JD, Williams WH, Mahoney EM, Huber PR, Block PC, Duke PG, et al. Off-pump vs conventional coronary artery bypass grafting: early and 1-year graft patency, cost, and quality-of-life outcomes: a randomized trial. JAMA. 2004;291:1841-9.

46. Nathoe HM, van Dijk D, Jansen EW, Suyker WJ, Diephuis JC, van Boven WJ, et al. A comparison of on-pump and off-pump coronary bypass surgery in low-risk patients. N Engl J Med. 2003;348:394-402.

47. Stone GW, Ellis SG, Cox DA, Hermiller J, O'Shaughnessy C, Mann JT, et al. A polymer-based, paclitaxel-eluting stent in patients with coronary artery disease. N Engl J Med. 2004;350:221-31.

48. Soares HP, Daniels S, Kumar A, Clarke M, Scott C, Swann S, et al. Bad reporting does not mean bad methods for randomised trials: observational study of randomised controlled trials performed by the Radiation Therapy Oncology Group. BMJ. 2004;328:22-4. 